\title{
Nuclear Factor Erythroid 2-Related Factor 2 Facilitates Neuronal Glutathione Synthesis by Upregulating Neuronal Excitatory Amino Acid Transporter 3 Expression
}

\author{
Carole Escartin, ${ }^{1,2}$ Seok Joon Won, ${ }^{1}$ Carole Malgorn, ${ }^{2}$ Gwennaelle Auregan, ${ }^{2}$ Ari E. Berman, ${ }^{1}$ Pei-Chun Chen, ${ }^{3}$ \\ Nicole Déglon, ${ }^{2}$ Jeffrey A. Johnson, ${ }^{3}$ Sang Won Suh, ${ }^{1}$ and Raymond A. Swanson ${ }^{1}$ \\ ${ }^{1}$ Department of Neurology, University of California San Francisco, and Neurology Service, San Francisco Veterans Affairs Medical Center, San Francisco, \\ California 94121, ${ }^{2}$ Commissariat à l'Energie Atomique et aux Energies Alternatives, CNRS, URA2210, Molecular Imaging Research Center, 92265 Fontenay- \\ aux-Roses, France, and ${ }^{3}$ School of Pharmacy, University of Wisconsin, Madison, WI 53705
}

Astrocytes support neuronal antioxidant capacity by releasing glutathione, which is cleaved to cysteine in brain extracellular space. Free cysteine is then taken up by neurons through excitatory amino acid transporter 3 [EAAT3; also termed Slcla1 (solute carrier family 1 member 1)] to support de novo glutathione synthesis. Activation of the nuclear factor erythroid 2-related factor 2 (Nrf2)-antioxidant responsive element (ARE) pathway by oxidative stress promotes astrocyte release of glutathione, but it remains unknown how this release is coupled to neuronal glutathione synthesis. Here we evaluated transcriptional regulation of the neuronal cysteine transporter EAAT3 by the Nrf2-ARE pathway. Nrf2 activators and Nrf2 overexpression both produced EAAT3 transcriptional activation in C6 cells. A conserved ARE-related sequence was found in the EAAT3 promoter of several mammalian species. This ARE-related sequence was bound by Nrf2 in mouse neurons in vivo as observed by chromatin immunoprecipitation. Chemical activation of the Nrf2-ARE pathway in mouse brain increased both neuronal EAAT3 levels and neuronal glutathione content, and these effects were abrogated in mice genetically deficient in either Nrf2 or EAAT3. Selective overexpression of Nrf2 in brain neurons by lentiviral gene transfer was sufficient to upregulate both neuronal EAAT3 protein and glutathione content. These findings identify a mechanism whereby Nrf2 activation can coordinate astrocyte glutathione release with neuronal glutathione synthesis through transcriptional upregulation of neuronal EAAT3 expression.

\section{Introduction}

Nuclear factor erythroid 2-related factor 2 (Nrf2) is a transcription factor that regulates expression of several antioxidant enzymes (Shih et al., 2003). Nrf2 translocates to the nucleus upon exposure to oxidants, where it forms heterodimers with small Maf proteins and binds to antioxidant responsive element (ARE) promoter sequences (Itoh et al., 1997). The Nrf2-ARE pathway coordinates cellular responses to oxidative stress in brain, and activation of this pathway can markedly reduce brain injury in experimental models of stroke, Parkinson's disease, and other neurological disorders (Vargas and Johnson, 2009). This salutary effect on neurons requires the production and extracellular re-

Received Dec. 17, 2010; revised March 8, 2011; accepted March 28, 2011.

Author contributions: C.E., S.W.S., and R.A.S. designed research; C.E., S.J.W., C.M., G.A., A.E.B., P.-C.C., and S.W.S performed research; N.D., and J.A.J. contributed unpublished reagents/analytic tools; C.E., S.J.W., and R.A.S. analyzed data; C.E., and R.A.S. wrote the paper.

This work was supported by the NIH (Grant P50 NS14543 to R.A.S.; and Grant R01 ES10042 to J.A.J.), the Department of Veterans Affairs Merit Review Program (R.A.S.), and Centre National de la Recherche Scientifique and Commissariat à l'Energie Atomique et aux Energies Alternatives (C.E.). We thank C. Hefner, M. Chaigneau, M. Guillermier, D. Houitte and, F. Petit for expert technical assistance. We are grateful to Dr. E. Brouillet, Dr. G. Bonvento, and Dr. M.C. Gaillard for helpful scientific discussions.

Correspondence should be addressed to Dr. Carole Escartin, CEA CNRS URA 2210, MIRCen, 18, route du Panorama, 92265 Fontenay-aux-Roses, France. E-mail: carole.escartin@cea.fr.

DOI:10.1523/JNEUROSCI.6577-10.2011

Copyright $\odot 2011$ the authors $\quad 0270-6474 / 11 / 317392-10 \$ 15.00 / 0$ lease of GSH (a tripeptide of glutamate, cysteine, and glycine) by astrocytes (Vargas and Johnson, 2009). However, neurons cannot directly acquire GSH from the extracellular space, and the mechanism by which astrocyte GSH release supports neuronal antioxidant status is not known.

Mature neurons, unlike most other cell types, use extracellular cysteine rather than cystine (cysteine disulfide) to synthesize GSH de novo (Dringen and Hirrlinger, 2003). Extracellular cysteine in brain is cleaved from GSH released by astrocytes (Dringen et al., 2001) and is taken up by neurons through excitatory amino acid transporter 3 (EAAT3). EAAT3, also termed solute carrier family 1 member 1 (Slcla1), was first identified as a highaffinity glutamate transporter (Kanai and Hediger, 1992) but was later shown to also transport cysteine in neuronal cultures (Chen and Swanson, 2003; Himi et al., 2003) and heterologous expression systems (Zerangue and Kavanaugh, 1996). EAAT3 is ubiquitously expressed in neurons, but not astrocytes, and has a predominately nonsynaptic localization (Danbolt, 2001). Inhibition of EAAT3 transport reduces both neuronal GSH content and neuronal survival after oxidative stress in vitro (Chen and Swanson, 2003; Nafia et al., 2008; Watabe et al., 2008). Similarly, EAAT3-deficient mice display reduced neuronal GSH levels, increased sensitivity to oxidants, accelerated age-related neuronal death, and cognitive deficits (Aoyama et al., 2006). EAAT3 thus 
plays an important role in neuronal defense against oxidative stress.

Several studies have shown EAAT3 activity to be regulated in part by trafficking between the cytosol and the plasma membrane (Robinson, 2006), but little is known about EAAT3 transcriptional regulation. EAAT3 expression is increased by hypoxia (Hsu et al., 2001), anesthetics (Huang and Zuo, 2003), and alltrans retinoic acid/RAR $\beta$ (Bianchi et al., 2009). The regulatory factor X1 has been shown to bind to the EAAT3 promoter and activate EAAT3 transcription (Ma et al., 2006), but the factors regulating EAAT3 transcription in the context of oxidative stress remain undefined. Results of the present studies show that EAAT3 is transcriptionally upregulated through the Nrf2-ARE pathway and that the resultant increase in EAAT3 expression promotes neuronal GSH synthesis. These findings identify a mechanism whereby astrocyte GSH release can be coupled to neuronal GSH synthesis in response to oxidative stress.

\section{Materials and Methods}

Reagents and plasmids. Reagents were obtained from Sigma except where otherwise noted. For cell culture experiments, L- sulforaphane (SR) and tert-butylhydroquinone ( $\mathrm{t}-\mathrm{BHQ}$ ) were prepared as concentrated stocks in ethanol and were diluted in culture medium just before use. The final concentration of ethanol was $<0.025 \%$. Rabbit antibody against EAAT3 was a kind gift from Dr. J. Rothstein (John Hopkins University, Baltimore, MD). The EAAT3-firefly luciferase plasmid (pEAAT3-luc) was a kind gift from Dr. Z. Zuo (University of Virginia, Charlottesville, VA). This plasmid has the human EAAT3 promoter region (bases -1 to -482 , relative to the start codon) inserted into the pGL3-luc plasmid (Promega) (Ma et al., 2006). The plasmids containing the mouse cDNA for Nrf2 (pNrf2) and Nrf2M (pNrf2M, a mutant, dominant-negative form of Nrf2) under the elongation factor $1 \alpha$ promoter and the corresponding empty vector ( $\mathrm{pF} 2 \mathrm{C})$, were kind gifts from Dr. J. Alam (Ochsner Clinic Foundation, New Orleans, LA) (Alam et al., 1999).

Cell cultures and transfection. Rat C6 glioma cells (ATCC) were grown in DMEM (Invitrogen) with 5\% fetal bovine serum (FBS), 2 mM glutamine, $100 \mathrm{U} / \mathrm{ml}$ penicillin, and $100 \mu \mathrm{g} / \mathrm{ml}$ streptomycin. They were used for 15-20 passages without noticeable change in morphology or response to treatment. Cells were used for transfection when $70-80 \%$ confluent. The following volumes and amounts are given for one well of a 24 well plate. Culture medium was replaced with $500 \mu \mathrm{l}$ of antibioticfree DMEM containing 5\% FBS and 2 mM glutamine. Plasmids [50 ng of pEAAT3-luc, $2.5 \mathrm{ng}$ of Renilla luciferase cDNA driven by the cytomegalovirus promoter (pCMV-RL, Promega), and 200 ng of pNrf2, pNrf2M, or pF2C] were diluted in $100 \mu \mathrm{l}$ of OptiMEM I Reduced serum medium (Invitrogen) in the presence of $1 \mu \mathrm{l}$ of Lipofectamine 2000 (Invitrogen). After $25 \mathrm{~min}, 100 \mu \mathrm{l}$ was added to each well and left for $24 \mathrm{~h}$, at which time the cells were used for experiments.

Promoter activity assays. Cultures were cotransfected with pEAAT3-luc and PCMV-RL. Cell lysates were prepared $24 \mathrm{~h}$ after transfection, and they were sampled sequentially for firefly luciferase activity followed by Renilla luciferase activity using the Dual-Luciferase Reporter assay (Promega) with a double-injector luminometer (Turner Biosystems). The luminescence values were corrected for background luminescence measured in nontransfected samples, and the firefly luciferase activity was normalized to Renilla luciferase activity to control for any variations in transfection efficiency and for nonspecific effects of treatments on gene expression.

EAAT3 transporter function. Cells grown in 48 well plates were rinsed with warm balanced salt solution (BSS) containing the following: $140 \mathrm{~mm}$ $\mathrm{NaCl}, 3.1 \mathrm{~mm} \mathrm{KCl}, 1.2 \mathrm{~mm} \mathrm{CaCl}_{2}, 1.2 \mathrm{~mm} \mathrm{MgSO}_{4}, 0.5 \mathrm{~mm} \mathrm{KH}_{2} \mathrm{PO}_{4}, 2 \mathrm{~mm}$ glucose, and $5 \mathrm{~mm}$ 1,4-piperazinediethanesulfonic acid, pH 7.2, 280-320 mOsm. Cells were preincubated for $20 \mathrm{~min}$ in BSS at $37^{\circ} \mathrm{C}$. Uptake was initiated by the addition of $100 \mu \mathrm{M}$ D-aspartate with $60 \mu \mathrm{Ci} / \mathrm{L}{ }^{14} \mathrm{C}-\mathrm{D}-$ aspartate (specific activity: $55 \mathrm{Ci} / \mathrm{mol}$; ARC). After $6 \mathrm{~min}$, incubation medium was aspirated, and cells were rinsed three times with cold HBSS (Invitrogen) and lysed in $0.1 \mathrm{~N} \mathrm{NaOH}$ with $0.01 \%$ SDS. Aliquots of the
A

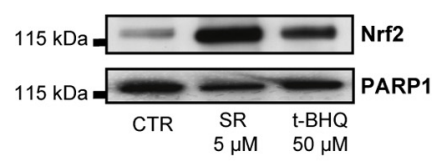

B
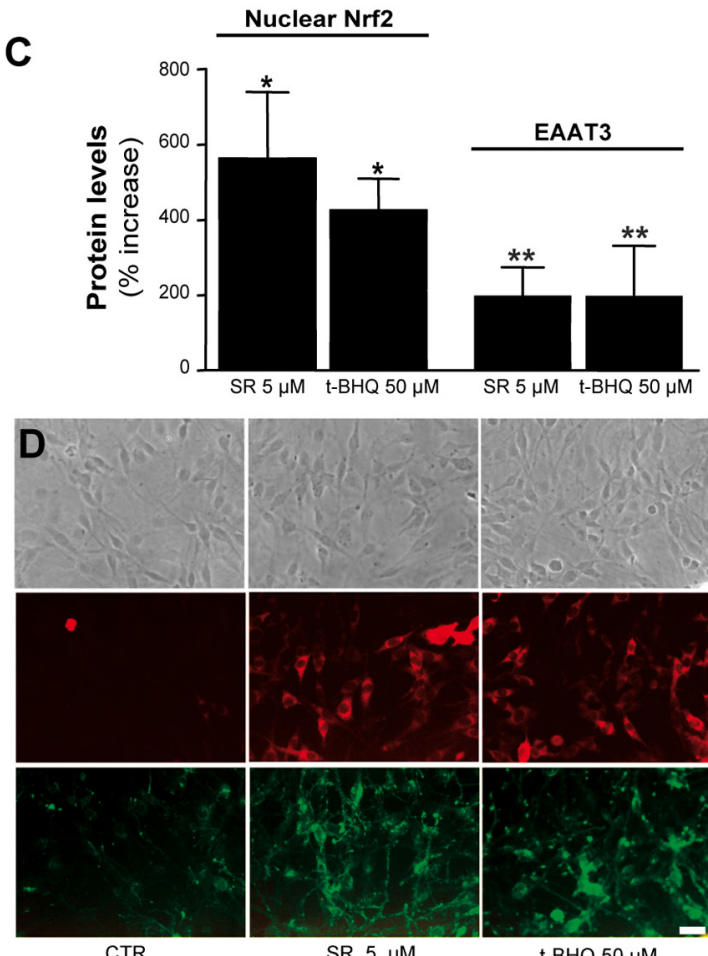

Phase contrast

E

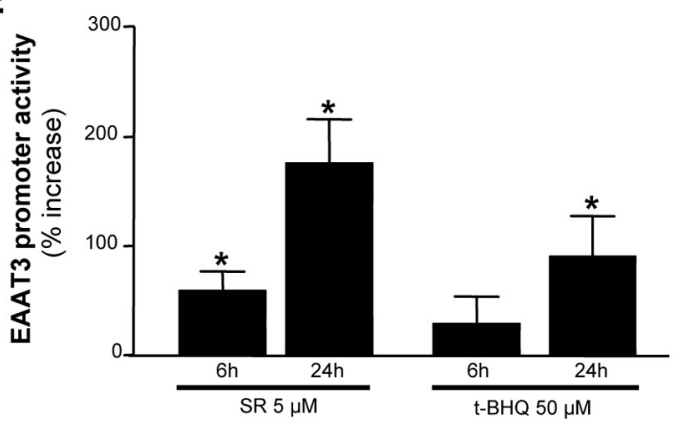

Figure 1. Activators of the Nrf2-ARE pathway increase EAAT3 expression at the transcriptional level. $\boldsymbol{A}, \boldsymbol{B}$, Cells were exposed for $48 \mathrm{~h}$ to $\mathrm{SR}$ or $\mathrm{t}-\mathrm{BHQ}$, and the nuclear accumulation of Nrf2 $(\boldsymbol{A})$ and EAAT3 expression $(\boldsymbol{B})$ were assessed by Western blot. $\boldsymbol{C}$, Nrf2 and EAAT3 band densities were normalized to the corresponding PARP-1 and actin band densities, respectively, and expressed as the percentage increase over controls (CTR). $n=3-8 .{ }^{*} p<0.05,{ }^{* *} p<$ 0.005 versus CTR. D, Immunostaining for EAAT3 and H0- 1 in cells exposed to SR or t-BHQ. Scale bar, $10 \mu \mathrm{m} . \boldsymbol{E}$, EAAT3 promoter activity was assessed using cells exposed to $\mathrm{SR}$ and $\mathrm{t}-\mathrm{BHQ}$ and transfected with the pEAAT3-luc and pCMV-RL plasmids. $n=3-4 .{ }^{*} p<0.05$ versus CTR.

lysate were taken for scintillation counting and protein determination by the bicinchoninic acid method (BCA) (Pierce) (Smith et al., 1985). For each condition, a parallel assay was performed in the presence of $200 \mu \mathrm{M}$ DL-threo-benzyloxyaspartate (TBOA, Tocris Bioscience). EAAT3-mediated ${ }^{14} \mathrm{C}$-D-aspartate uptake was calculated as the difference between total uptake and TBOA-insensitive uptake, after normalization to protein content. ${ }^{14} \mathrm{C}$-D-aspartate uptake was found to increase linearly for up to 10 min of incubation. The fraction not inhibited by TBOA (EAAT3independent uptake) was $<20 \%$ of total uptake and not modified by any treatment. Uptake value in controls was $377 \pm 38$ pmol D-aspartate $\cdot \min ^{-1} \cdot$ mg protein $^{-1}$. 
Immunostaining. C6 glioma cells grown on a glass coverslip were rinsed with warm $10 \mathrm{~mm}$ PBS and fixed for $15 \mathrm{~min}$ in $4 \%$ paraformaldehyde. After three rinses with PBS, cells or floating fixed brain sections were incubated for 30 min in $10 \mathrm{~mm}$ PBS with $2 \%$ normal goat serum, $0.2 \%$ Triton X-100, and $0.1 \%$ (w/v) BSA. Cells or sections were then incubated overnight at $4^{\circ} \mathrm{C}$ with antibodies to $\beta$-galactosidase (1:1000, Invitrogen), EAAT3 (1:400), GFAP, (1:1000, Dako), heme oxygenase-1 (HO-1) (1:200; OSA-111, Stressgene), or NeuN (1:1000, Millipore Bioscience Research Reagents) in the same buffer. After three rinses with PBS, they were incubated for $2 \mathrm{~h}$ at room temperature with secondary antibodies coupled to Alexa Fluor (1:500, Invitrogen). To detect GSH in situ, we used two techniques: labeling with C5-maleimide (Aoyama et al., 2006; Won et al., 2010) and detection of GSH-Nethylmaleimide (NEM) adducts (Miller et al., 2009). For C5-maleimide staining, the sections were incubated overnight at $4^{\circ} \mathrm{C}$ with $2.5 \mathrm{~mm}$ Alexa Fluor488 or Alexa Fluor 594 C5maleimide (Invitrogen) in $0.1 \mathrm{M}$ phosphate buffer containing $0.3 \%$ Triton X-100. For GSH-NEM detection, the sections were incubated with $10 \mathrm{~mm} \mathrm{NEM}$ for $4 \mathrm{~h}$ at $4^{\circ} \mathrm{C}$, washed, and incubated with a monoclonal antibody to GSH-NEM (clone 8.1GSH, Millipore). Antibody binding was then tagged using secondary antibodies coupled to Alexa Fluor (1:500, Invitrogen). Sections were mounted onto a glass slide, and images were taken with a Zeiss confocal fluorescence microscope, using the same settings for all conditions. All sections were stained and photographed in parallel by an individual blinded to the experimental conditions. C5-maleimide and EAAT3 staining fluorescent intensity was measured, using ImageJ software (NIH), in 20 randomly selected perikarya in each of two to four fields to generate an average value for each mouse. GSHNEM immunostaining intensity was measured over the entire field of interest and normalized to the intensity of the contralateral striatum. In mice injected with lenti-Nrf2 or lenti-LacZ, quantification of C5-maleimide or EAAT3 staining intensity was performed on 20 GFPpositive cells on each mouse and injection side using ImageJ software.

Western blots. Cells were quickly rinsed with warm $10 \mathrm{~mm}$ PBS and lysed in $50 \mathrm{~mm}$ Tris- $\mathrm{HCl}$, $\mathrm{pH}$ 7.4, $100 \mathrm{~mm} \mathrm{NaCl}, 1 \%$ SDS, and protease inhibitor (Roche). Protein homogenates were collected on ice, sonicated, and diluted in Laemmli buffer. Subcellular fractionation to obtain nuclear fractions was performed according to the method of Vargas et al. (2005). Protein concentration was determined using the BCA method. Protein samples were boiled for $5 \mathrm{~min}$, loaded on a $10 \%$ acrylamide gel, submitted to SDS-PAGE, and transferred to a PVDF membrane. Membranes were blotted with the following antibodies diluted in Tris buffer saline with $0.1 \%$ Tween-20 and 5\% milk proteins: actin (1:10,000), EAAT3 (1:400), HO-1 (1:2000; SPA-896, Stressgene), Nrf2 (1:200; sc-722, Santa Cruz Biotechnology), and poly (ADP-ribose) polymerase 1 (PARP-1) (1:1000; Trevigen). After three 10 min rinses, secondary antibodies coupled to horseradish peroxidase (Vector Laboratories) were incubated with the membrane at a

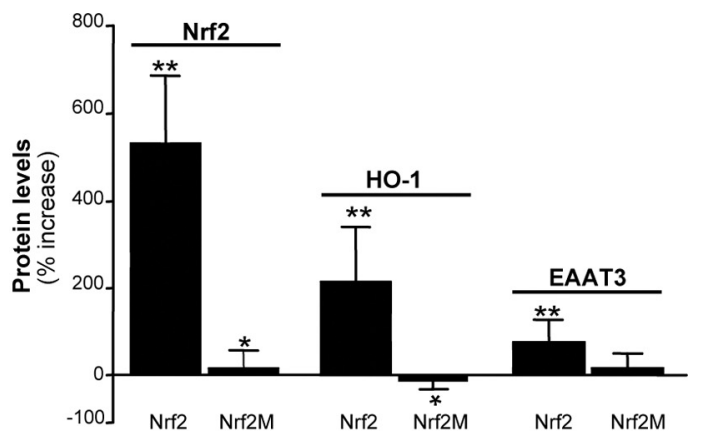

Figure 2. Nrf2 overexpression increases EAAT3 transcription. Cells were transfected for $24 \mathrm{~h}$ with a plasmid encoding Nrf2, a dominant-negative Nrf2 mutant (Nrf2M), or the empty vector [control (CTR)]. Protein expression was assessed by Western blot, and band density was normalized to actin and expressed relative to CTR. $n=4-5 .{ }^{* *} p<0.01$ versus $\mathrm{CTR}^{*}{ }^{*} p<0.05$ versus Nrf2.

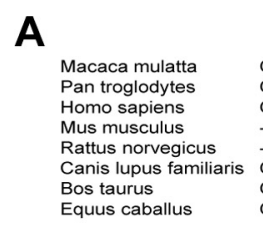

B
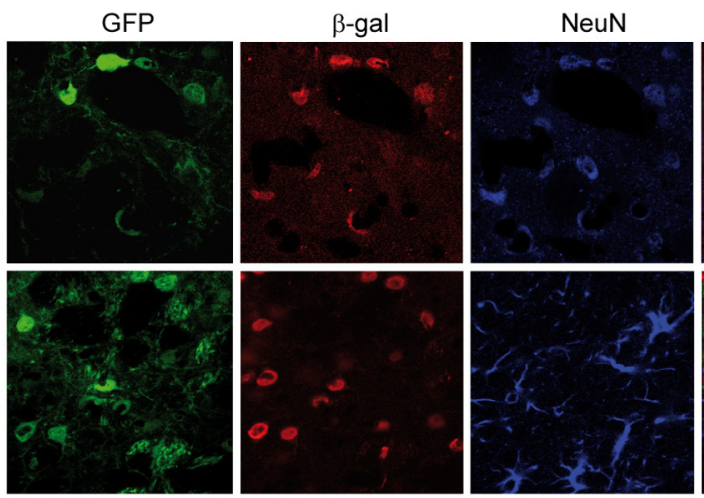

$\beta-$ gal

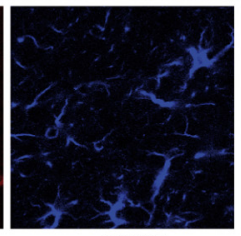

GFAP

D
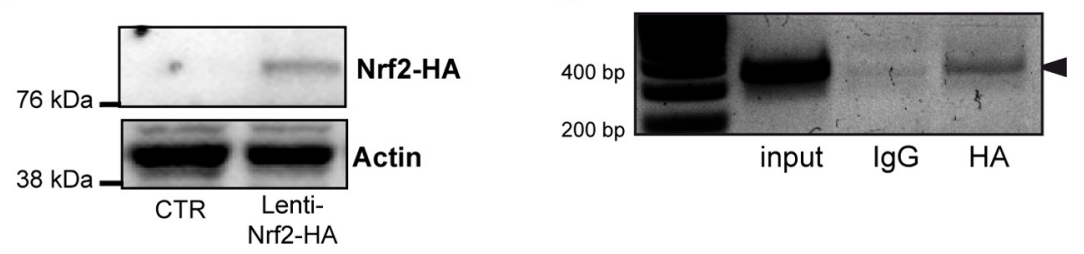

Figure 3. Nrf2 binds to the ARE-related sequence in the EAAT3 promoter in neurons. $\boldsymbol{A}$, The ARE-related sequence (box) is located in a conserved promoter region of the EAAT3/S/C1a1 gene in various mammalian species. The position of the first base of the ARE-related sequence $\left(^{*}\right)$ is given relative to the start codon for each species. The core sequence is highlighted in gray. $\boldsymbol{B}$, Lentiviral vectors infect neurons selectively. After a double infection with lenti-Lac $Z$ and lenti-GFP, cells that are GFP and $\beta$-galactosidase positive coexpress the neuronal marker NeuN and not the astrocytic marker GFAP. Scale bar, $20 \mu \mathrm{m}$. C, Western blotting of brain samples from mice injected with lenti-Nrf2-HA. Antibody to the HA tag detects a band corresponding to Nrf2 only in the brains injected with lenti-Nrf2-HA. D, Chromatin from lenti-Nrf2-HA injected mice was immunoprecipitated with lgG antibody to HA or with control lgG, and the ARE-related sequence on the EAAT3 promoter was amplified by PCR using specific primers. Nrf2 binds selectively to the ARE-related sequence on the EAAT3 mouse promoter. Image is representative of three PCR runs.

1:10,000 dilution for $1 \mathrm{~h}$. Antibody binding was detected on $\mathrm{x}$-ray films using the ECL or ECL plus substrate (GE Healthcare). Films were scanned and intensities of bands were measured using Image J and normalized to actin or PARP-1. Nrf2 and EAAT3 antibody specificity was controlled by Western blot using cells overexpressing Nrf2 and brain samples from $E A A T 3^{-/-}$and EAAT3 ${ }^{+/+}$mice (data not shown).

Pharmacological treatments in mice. These experiments were approved by the San Francisco Veterans Affairs Medical Center animal studies committee and were in strict accordance with the recommendations of 

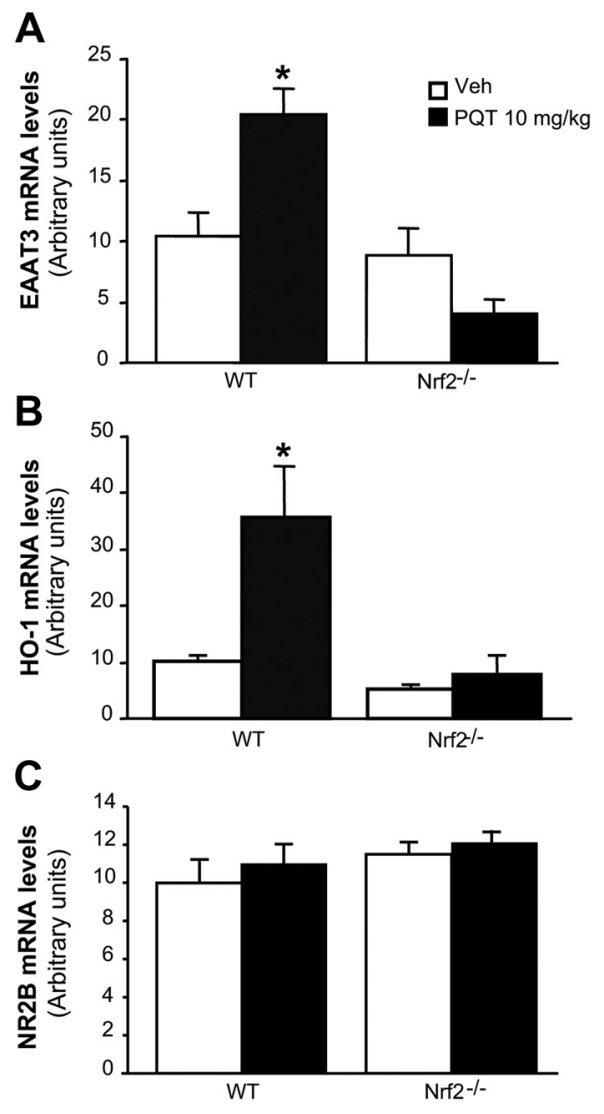

Figure 4. $P Q T$ increases brain EAAT3 mRNA levels in an Nrf2-dependent manner. WT and $\mathrm{Nrf2}{ }^{-1-}$ mice received an intraperitoneal injection of $10 \mathrm{mg} / \mathrm{kg} \mathrm{PQT}$ or saline vehicle (Veh), and the frontal cerebral cortex was collected $24 \mathrm{~h}$ later. $A-C$, EAAT3 $(\boldsymbol{A}), \mathrm{HO}-1(\boldsymbol{B})$, and NR2B (C) mRNA levels were analyzed by qRT-PCR and normalized to GAPDH mRNA levels. $n=3-5 .{ }^{*} p<$ 0.05 versus all groups.

the European Communities Council (86/609/EEC). WT C57BL/6 mice were obtained from Simonsen, and Nrf2 ${ }^{-1-}$ mice on the C57BL/6 background were kindly provided by Dr. Y. W. Kan (University of California, San Francisco, CA). EAT3 ${ }^{-1-}$ mice on a CD1 background (Aoyama et al., 2006) had been outbred on the C57BL/6 background for six generations prior to these experiments. Mice were housed with a $12 \mathrm{~h}$ light/dark cycle and were given food and water ad libitum. Three-month-old male mice were used for all studies. Paraquat [1,1'-dimethyl-4,4'-bipyridium (PQT); $1 \mathrm{mg} / \mathrm{ml}$ in sterile saline] was administered at $10 \mathrm{mg} / \mathrm{kg}$ by intraperitoneal injection. Controls received equal volumes of saline vehicle alone. Mouse brains were harvested $24 \mathrm{~h}$ after injection, $2 \mathrm{~mm}$ coronal sections were prepared, and the frontal cortex was dissected out on ice. Samples were stored in RNAlater (Qiagen) until mRNA extraction. t-BHQ (100 mM in $10 \%$ ethanol) was administered $(1 \mu \mathrm{l})$ by stereotaxic injection into the striatum over 10 min using a 33 gauge Hamilton syringe (anteroposterior + $1 \mathrm{~mm}$, mediolateral $2 \mathrm{~mm}$ from bregma, ventral $-2.5 \mathrm{~mm}$ ). The needle was withdrawn after an additional $5 \mathrm{~min}$. Forty-eight hours later, the mice were transcardially perfused with $0.9 \%$ saline for 5 min followed by $4 \%$ paraformaldehyde for $10 \mathrm{~min}$, and the brains were cryoprotected with sucrose and cut into $50 \mu \mathrm{m}$ coronal sections with a cryostat. Buthionine sulfoxi-

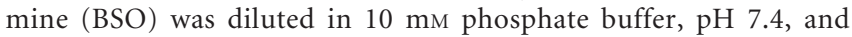
injected (1.3 g/kg, i.p.), while mice received intracerebral t-BHQ or vehicle injections. Mice received an additional BSO injection after $24 \mathrm{~h}$ and were perfusion fixed $24 \mathrm{~h}$ later.

Lentivirus production and injection. Self-inactivating (SIN) lentiviral vectors containing the central polypurine tract (cPPT) sequence, the mouse phosphoglycerate kinase I promoter (PGK), the woodchuck postregulatory element (WPRE) sequence (Déglon et al., 2000), and encoding mouse Nrf2 tagged with hemagglutinin (HA) were produced. To clone Nrf2-HA cDNA, a PCR was performed using the $\mathrm{pNrf} 2$ plasmid as a template, and the ampli- con was cloned into the SIN-cPPT-PGK-Nrf2-HA-WPRE plasmid. Lentiviral vectors (lenti-Nrf2-HA) were produced in 293T cells and pseudotyped with the vesicular stomatitis virus G-protein (Déglon et al., 2000). Control vectors contain the $\beta$-galactosidase gene (lenti-LacZ). Mice received stereotaxic injections of lenti-LacZ and lenti-Nrf2-HA in the left and right striatum respectively under ketamine-xylazine anesthesia. Suspensions of lentiviral vectors diluted in PBS $+1 \%$ BSA (100 ng of p24/ $\mu \mathrm{l}, 2 \mu \mathrm{l})$ were administered at a rate of $0.2 \mu \mathrm{l} / \mathrm{min}$. A lentiviral vector encoding the GFP gene was coinjected (50 ng of p24) with lenti-LacZ or lenti-Nrf2-HA to detect infected, GFP-positive neurons on immunostained brain sections because neurons are coinfected by the two viruses (see Fig. $3 A$ ). Coinjection with lenti-GFP also allowed identification and selective dissection of the GFP-positive area from fresh slices under a fluorescent microscope for quantitative reverse transcriptase PCR (qRT-PCR) analysis and chromatin immunoprecipitation.

$q R T-P C R$. Total RNA was extracted from brain samples with Trizol and treated with DNase (Qiagen). cDNA was synthesized from $1 \mu \mathrm{g}$ of total RNA and random oligo primers using the SuperScript III first strand kit (Invitrogen). Twenty nanograms of cDNA were used in triplicate to perform realtime PCR using the Light Cycler 480 SybrGreen I Master kit (Roche) and the 7900HT Fast Real-Time PCR System. The following sets of primers were designed with the Primer Express Software (Applied Biosystems) except where a reference is cited: mouse EAAT3 $5^{\prime}$-ATGTGCTACATGCCGATTGG $-3^{\prime}$ (forward), 5' -CTCAGGACAGTGGCCATGTAAA-3' (reverse); mouse HO-1 5' -GTGATGGAGCGTCCACAGC-3' (forward), 5' -TGGTGGCCTCCTTCAAGG-3' (reverse) (Pugazhenthi et al., 2007); mouse NR2B 5'-GCTACAACACCCACGAGAAGAG-3' (forward), 5'-GAGAGGGTCCACGCTTTCC-3' (reverse); mouse Nrf2 5' -TGAGTCGCTTGCCCTGGATAT (forward), 5'-AGTCATGGCTGCCTCCAGAGA-3' (reverse); and mouse glyceraldehyde 3-phosphate dehydrogenase (GAPDH) 5'-TGGCAAAGTGGAGATTGTTGCC-3' (forward), 5' -AAGATGGTGATGGGCTTCCCG-3' (reverse) (Rhinn et al., 2008). A dissociation step was added at the end of the PCR to confirm the amplification of a single product. For each set of primers, the efficiency of the amplification reaction was measured using a 10-fold dilution standard curve, and found to be 87 to $97 \%$. No-template and no-reverse transcriptase controls were included in each assay, and these produced no detectable signal during the 40 cycles of amplification. EAAT3, NR2B, Nrf2, and HO-1 mRNA levels were normalized to GAPDH levels and expressed relative to levels in control animals using the $2^{-\Delta \Delta \mathrm{Ct}}$ method (Livak and Schmittgen, 2001).

Chromatin immunoprecipitation. Six mice were injected with lentiNrf2-HA and lenti-GFP in the right striatum to produce stable Nrf2-HA overexpression in neurons (de Almeida et al., 2001). One month later, the mice were killed, the brains were collected, and punches were dissected out of the $\mathrm{GFP}^{+}$area. Pooled punches were cross-linked in $1 \%$ formaldehyde for $15 \mathrm{~min}$. After addition of $125 \mathrm{~mm}$ glycine for $5 \mathrm{~min}$, samples were rinsed three times in PBS with protease inhibitors and frozen until further processing. Nuclear extraction, chromatin purification, and immunoprecipitation were performed by the University of California, Davis Genome Center as described by O'Geen et al. (2010). Immunoprecipitation used IgG antibodies to HA (Covance) and control IgG antibodies. PCR was performed on chromatin pulled down with the antibodies and, as a positive control, on $0.25 \%$ of chromatin input. The following primers were used to amplify the ARE-related sequence on the EAAT3 promoter (amplicon size: $350 \mathrm{bp}$ ): 5' -TCCCATATCAAATCCCTTCGC-3' (forward) 5' -TTTGCGATGAGTCGGGTAGC -3' (reverse). Amplicons were run on a 1.5\% agarose gel.

Statistical analysis. Data are expressed as means \pm SEM. For studies in cell culture, multiple group comparisons were performed by the nonparametric Kruskal-Wallis test followed by the Mann-Whitney post hoc test. The $n$ value indicates the number of independent culture preparations, and measurements were performed in triplicate for each $n$. In vivo studies were evaluated with either the paired $t$ test or with ANOVA and Fisher's post hoc least significant difference test of the designated treatment groups, with $n$ equal to the number of mice in each group.

\section{Results}

Stimulation of the Nrf2-ARE pathway increases EAAT3 expression and function

We first evaluated the effects of Nrf2-ARE pathway activation on EAAT3 transcriptional regulation in the C6 glioma cell line, which 
exhibits endogenous EAAT3 expression (Davis et al., 1998). Cells were treated for $48 \mathrm{~h}$ with two established nucleophile activators: SR and t-BHQ (Kraft et al., 2004). We confirmed that these compounds activate the Nrf2-ARE pathway under the conditions of these studies by measuring nuclear translocation of Nrf2 (Fig. 1A,C) and upregulation of $\mathrm{HO}-1$, an established transcriptional target of Nrf2 (Fig. 1D) (Alam et al., 1999). SR and t-BHQ also increased EAAT3 expression, as shown by Western blot (Fig. $1 B, C$ ) and immunostaining (Fig. 1D).

EAAT3 function was then measured as the TBOA-sensitive uptake of ${ }^{14} \mathrm{C}$-Daspartate, a stable and nonmetabolized substrate of EAAT3 (Erecińska et al., 1983; Himi et al., 2003). EAAT3 is the only subtype of the EAAT family expressed by C6 glioma cells (Davis et al., 1998) such that TBOA-sensitive uptake of ${ }^{14} \mathrm{C}$-D-aspartate provides a specific measure of EAAT3 function. The increase in EAAT3 expression induced by SR and t-BHQ treatment was accompanied by a $51.3 \pm 13.9 \%$ and $49.2 \pm$ $12.3 \%$ increase in EAAT3 function $(p<$ $0.05, n=6)$.

EAAT3 transcriptional activation was evaluated using a reporter gene construct (pEAAT3-luc), in which the human EAAT3 promoter drives expression of firefly luciferase (Ma et al., 2006). Cells were cotransfected with pEAAT3-luc and a plasmid in which the Renilla luciferase gene is constitutively expressed under control of the cytomegalovirus promoter. Firefly and Renilla luciferase activities were assessed $24 \mathrm{~h}$ after transfection on cells exposed to SR or t-BHQ for 6 or $24 \mathrm{~h}$. Both nucleophiles increased firefly luciferase activity, indicating activation of the EAAT3 promoter (Fig. 1E).

\section{Overexpression of $\mathrm{Nrf} 2$ increases \\ EAAT3 expression}

To determine whether Nrf2 directly regulates EAAT3 transcription, we transfected C6 glioma cells with plasmids coding for pNrf2 or Nrf2M, a dominant-negative form of Nrf2 (Alam et al., 1999). Transfection with pNrf2 produced a large increase in Nrf2 expression and a similar large increase in HO-1 expression (Fig. 2). Overexpression of Nrf2 also increased expression of EAAT3 protein (Fig. 2) and stimulated EAAT3 promoter activity by $45.50 \pm 10.51 \%$, as measured by the luciferase reporter assay $(p<0.01, n=4-5)$. The magnitude of this effect was smaller than observed with chemical Nrf2 activators (Fig. 1), possibly because only a fraction of the cells overexpressed Nrf2 (transfection efficiency $=40 \%$ ). Overexpression of the dominant-negative construct Nrf2M had no significant effect on EAAT3 protein levels (Fig. 2) or basal EAAT3 promoter activity $(-8.28 \pm 4.39 \%, p>0.05)$, suggest-
WT
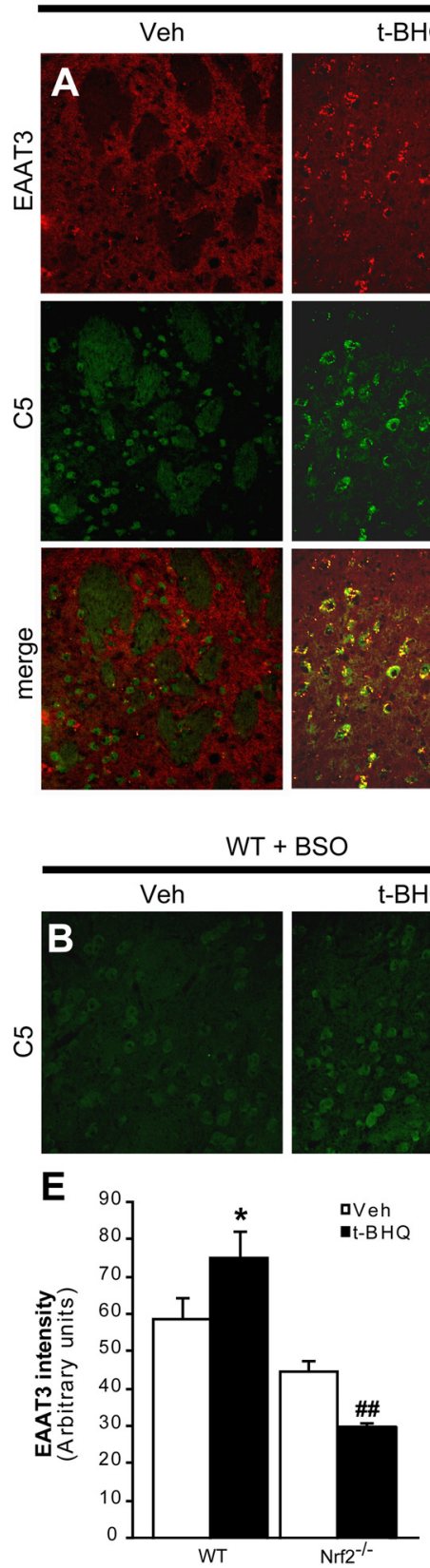

$\mathrm{t}-\mathrm{BHQ}$
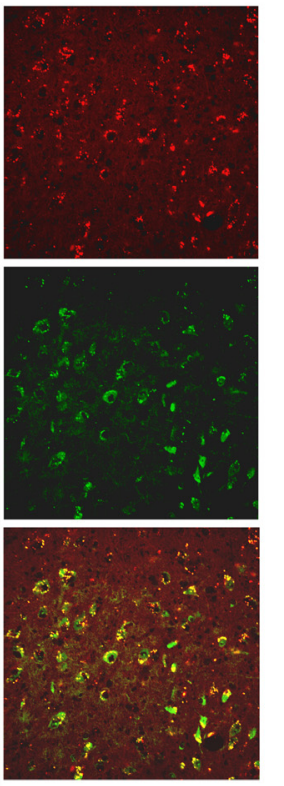

$\mathrm{NT}+\mathrm{BSO}$

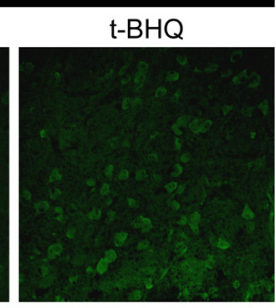

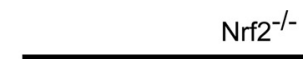
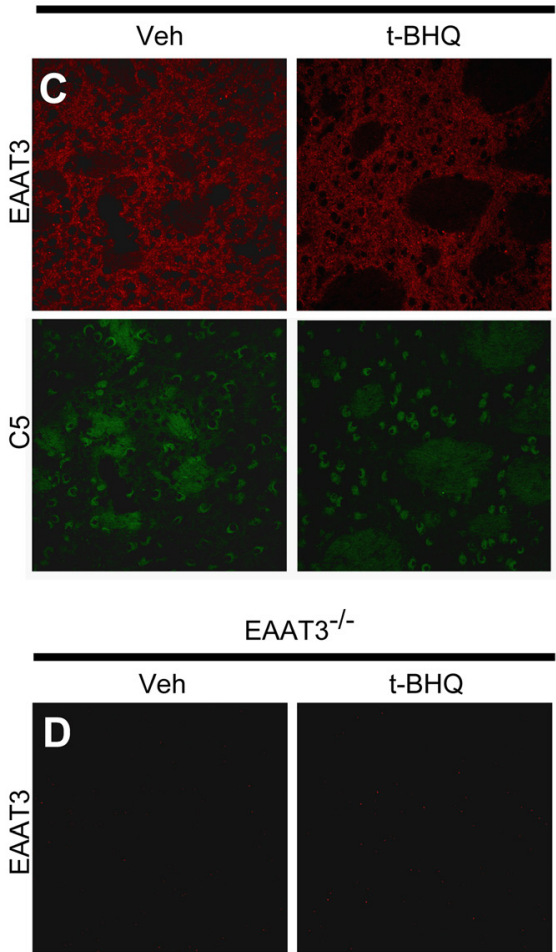

EAAT3 ${ }^{-/-}$
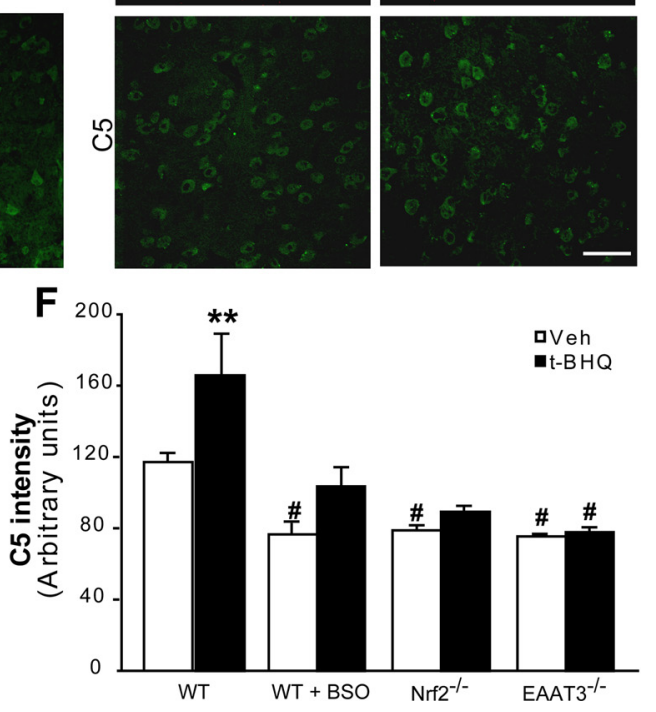

Figure 5. $\mathrm{t}-\mathrm{BHQ}$ increases neuronal EAAT3 expression and GSH levels in an Nrf2- and EAAT3-dependent manner. Striata of WT, $\mathrm{Nrf}^{-1-}$, and EAAT3 ${ }^{-1-}$ mice were injected with $1 \mu$ l of $100 \mathrm{~mm} \mathrm{t}-\mathrm{BHQ}$ or $10 \%$ ethanol vehicle (Veh) and harvested $48 \mathrm{~h}$ later. Photomicrographs show representative fields of the striatum near the injection sites, with EAAT3 identified by immunostaining (red) and GSH identified with (5-maleimide (green). $\boldsymbol{A}$, In WT mice, both GSH and EAAT3 expression are upregulated by t-BHQ. $\boldsymbol{B}$, Both basal $\mathrm{C} 5$-maleimide staining (C5) and the $\mathrm{t}-\mathrm{BHQ}$-mediated increase in $\mathrm{C5}$-maleimide staining are suppressed in mice that also received intraperitoneal injections of BSO . C, D, t-BHQ failed to increase neuronal EAAT3 expression and GSH content in Nrf2 ${ }^{-1-}$ mice $(\boldsymbol{C})$, EAAT3 $^{-1-}$ mice $(\boldsymbol{D})$, and in regions distant from the injection sites in WT mice (data not shown). Scale bar: (in $\left.\boldsymbol{D}\right) \boldsymbol{A}-\boldsymbol{D}$, $40 \mu \mathrm{m} . \boldsymbol{E}, \boldsymbol{F}$, Quantification of EAAT3 and GSH staining shows that t-BHQ increases EAAT3 and GSH only in WT mice. $n=3-5$. ${ }^{* *} p<0.005,{ }^{*} p<0.05$, versus all groups; ${ }^{\#} p<0.05,{ }^{\# \#} p<0.005$ versus WT Veh.

ing that Nrf2-ARE signaling is not required for basal EAAT3 expression.

Nrf2 directly binds to the ARE-related sequence of the neuronal EAAT3 promoter in vivo

Analysis of the human EAAT3 promoter revealed an ARE-related sequence $5^{\prime}$-ggTGACnnnG $\underline{G c}-3^{\prime}$ at position -142 to -133 , with the underline indicating the nonconventional part of the consen- 
A
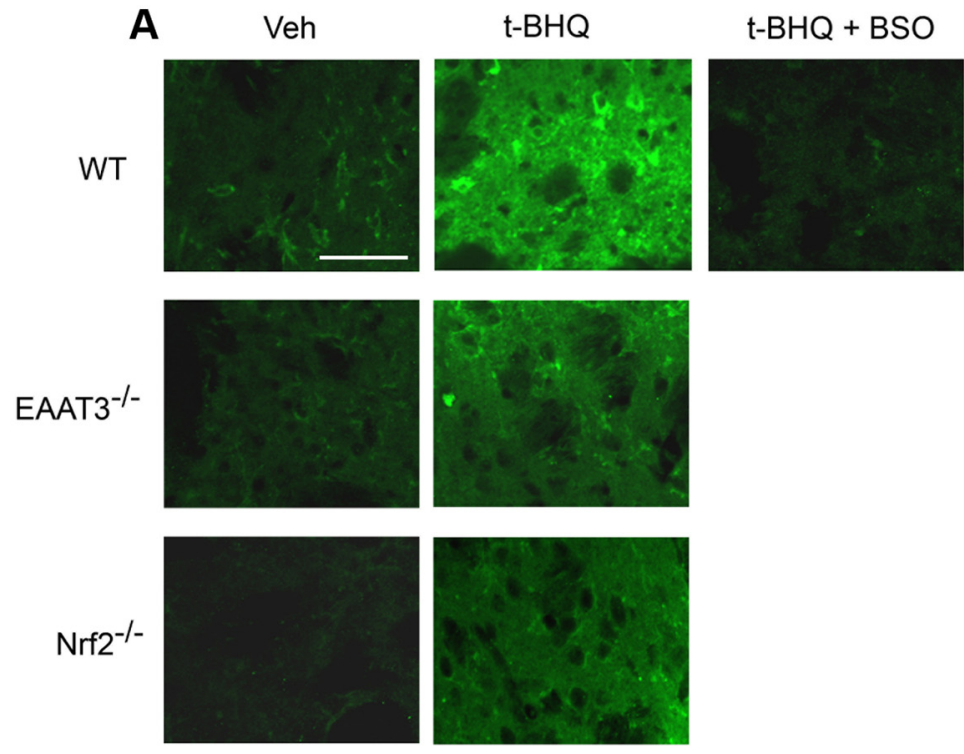

B

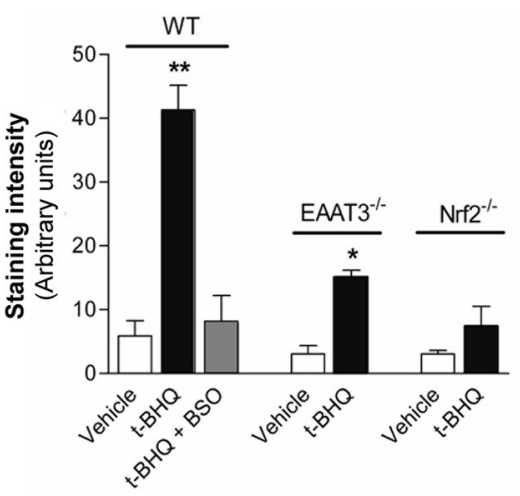

Figure 6. $\mathrm{t}-\mathrm{BHQ}$ increases GSH levels in an Nrf2-and EAAT3-dependent manner. $\boldsymbol{A}$, Striata from the mice shown in Figure 5 were also evaluated for GSH content using immunostaining for GSH-NEM adducts (green) following treatment of the sections with NEM. The increased GSH signal induced by t-BHQ was prevented by BSO and was absent at sites remote from the t-BHQ injections (data not shown). Images are representative of $n=3-5$ mice in each treatment group. Scale bar, $40 \mu \mathrm{m}$. $\boldsymbol{B}$, Quantified immunostaining. $n=3-5 .{ }^{* *} p<0.01,{ }^{*} p<0.05$ versus Veh in each genotype.

sus sequence and the capitalized letters indicating the core sequence (Wang et al., 2007). EAAT3 (Slc1a1) promoter sequences from eight mammalian species were retrieved and aligned with DiAlign Software (Genomatix) (Morgenstern et al., 1998). The multispecies alignment showed that the ARE-related sequence was in a conserved domain of the EAAT3 promoter and that the core sequence was present in all species (Fig. $3 A$ ).

To demonstrate that Nrf2 can bind to the EAAT3 promoter of neurons in situ, we performed chromatin immunoprecipitation (ChIP) using brain samples in which a neuron-targeted lentivirus (Fig. 3B) (de Almeida et al., 2001) was used to express HA-tagged Nrf2 in brain neurons. Western blots confirmed the presence of HA-tagged Nrf2 in brain samples from mice injected with the lentivirus encoding Nrf2-HA (lenti-Nrf2-HA) (Fig. 3C). ChIP analysis showed that the ARE-related sequence in the EAAT3 promoter was coimmunoprecipitated by an antibody to the HA tag but not by the control IgG antibody (Fig. 3D), indicating that Nrf2 binds to the ARE-related sequence of the EAAT3 promoter of mouse neurons in situ.

\section{Oxidant-induced increase in EAAT3 expression in mouse brain}

To determine whether oxidative stress can activate EAAT3 transcription in vivo through the Nrf2-ARE pathway, we measured
EAAT3 mRNA levels in the cerebral cortex of WT and Nrf2 ${ }^{-1-}$ mice after an intraperitoneal injection of a low dose of PQT, which generates intracellular superoxide through a recycling reaction with NADPH (Comporti, 1989). Basal EAAT3 mRNA levels were not significantly different between WT and $\mathrm{Nrf2} 2^{-1-}$ mice (Fig. $4 A)$. PQT increased HO-1 mRNA in WT mouse cortex by threefold (Fig. $4 B$ ), consistent with activation of the Nrf2-ARE pathway. PQT also increased EAAT3 mRNA levels in WT mouse cortex approximately twofold (Fig. $4 A$ ). In contrast, PQT did not increase EAAT3 mRNA expression in $\mathrm{Nrf2} 2^{-1-}$ mice. mRNA levels of the neuronal protein NR2B was similar in all groups (Fig. 4C), confirming that the changes in mRNA expression were not nonspecific or secondary to neuronal death.

\section{Activation of the Nrf2 pathway increases neuronal EAAT3 expression and neuronal GSH levels in mouse brain}

EAAT3 expression was evaluated by immunostaining $48 \mathrm{~h}$ after $\mathrm{t}-\mathrm{BHQ}$ injection into the striatum of WT and Nrf2 ${ }^{-1-}$ mice. $t-B H Q$ produced a significant increase in EAAT3 immunoreactivity in neurons near the injection site in WT mice, but not $N r f 2^{-1-}$ mice (Fig. $5 A, C, E)$. The functional effect of Nrf2induced EAAT3 expression was then evaluated using C5-maleimide (Aoyama et al., 2006; Won et al., 2010) to label GSH in fixed brain sections from WT, $\mathrm{Nrf2} 2^{-1-}$, and EAAT3 ${ }^{-1-}$ mice injected with t-BHQ or vehicle. $\mathrm{t}-\mathrm{BHQ}$ increased C5-maleimide staining over neuronal perikarya in the WT brains, and this staining appeared most intense in the neurons with the highest levels of EAAT3 expression (Fig. $5 A, F$ ). This increase was also evident in the neuropil, which contains both neuronal and astrocyte processes. By contrast, t-BHQ failed to produce an increase in $\mathrm{C} 5$-maleimide staining in the neurons of either $N r f 2^{-1-}$ or $E A A T 3^{-1-}$ mice (Fig. 5C,D,F). The t-BHQ-induced increase in C5-maleimide staining was blocked in WT mice coinjected with BSO (an inhibitor of the GSH-synthesizing enzyme gamma-glutamylcysteine ligase), thus confirming the specificity of GSH in situ detection by C5-maleimide (Fig. $5 B, F$ ). As additional confirmation, GSH was also labeled using antibody to the GSH-N-ethylmaleimide (NEM) adduct after incubating sections with NEM (Miller et al., 2009). GSH imaging by this method produced more signal in the neuropil than the C5-maleimide method, but the overall pattern of staining was the same: $t-B H Q$ injections produced large increase in GSH signal in WT mice, and much smaller increases in $N r f 2^{-/-}$or EAAT3 $3^{-1-}$ mice (Fig. 6).

Nrf2 overexpression in neurons increases EAAT3 expression and GSH levels

Because $t-B H Q$ can activate the Nrf2 pathway in both astrocytes and neurons, we used the neuron-targeted lentivirus (Fig. 3B) (de 
A

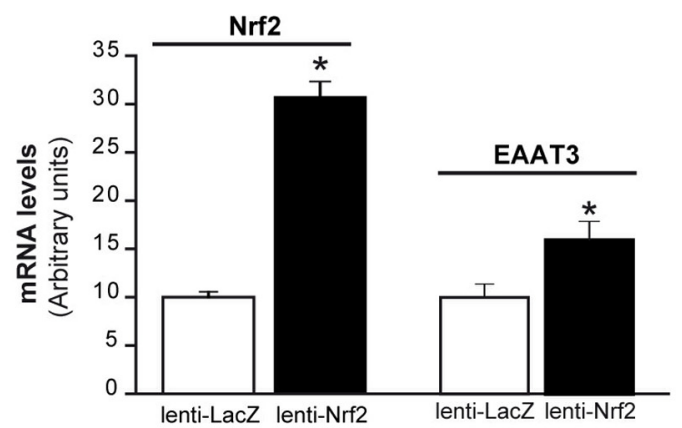

B

B lenti-LacZ
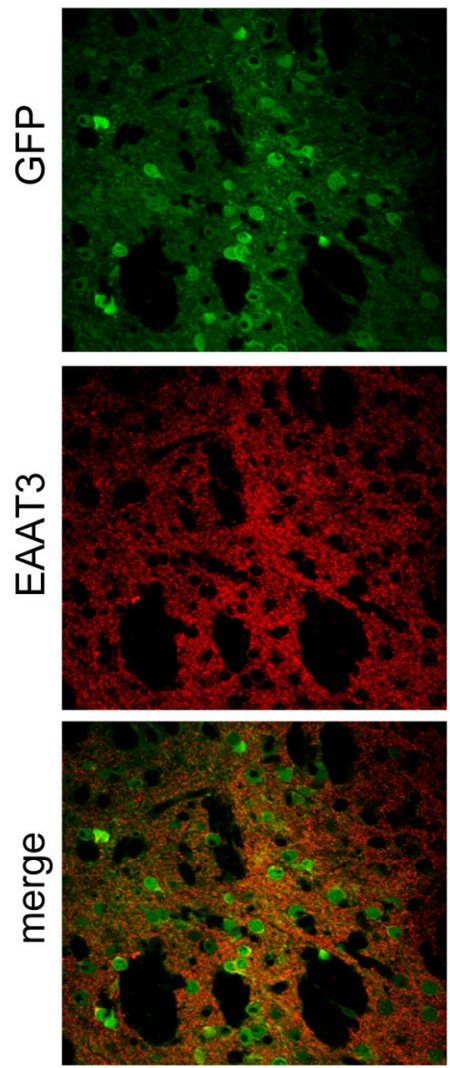

D

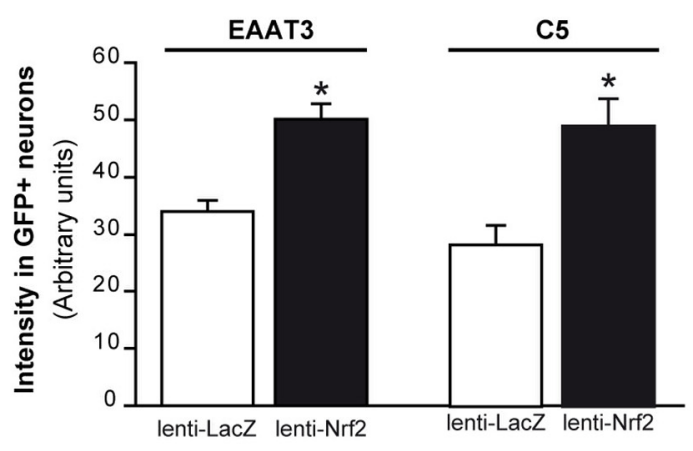

C
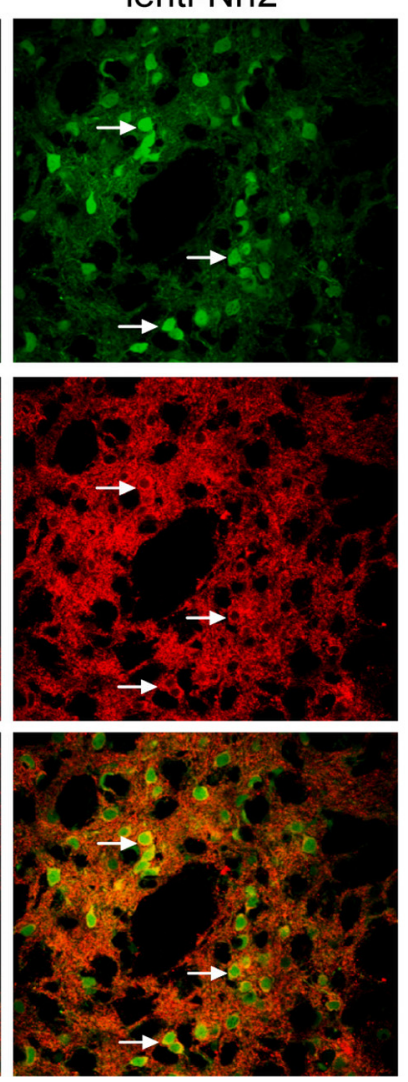

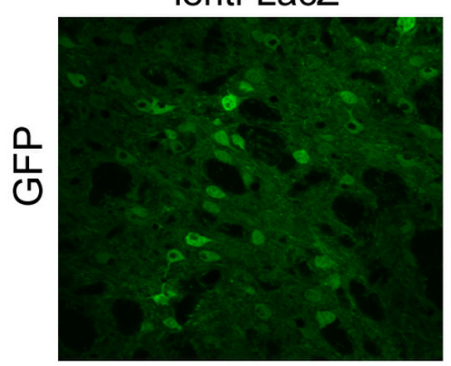

lenti-LacZ
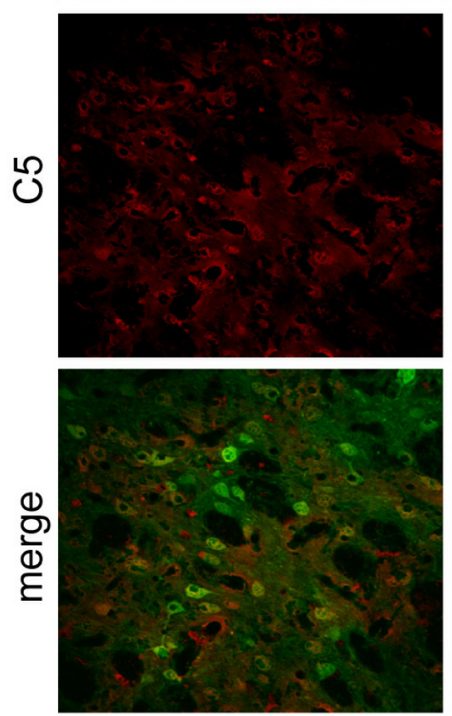

lenti-Nrf2
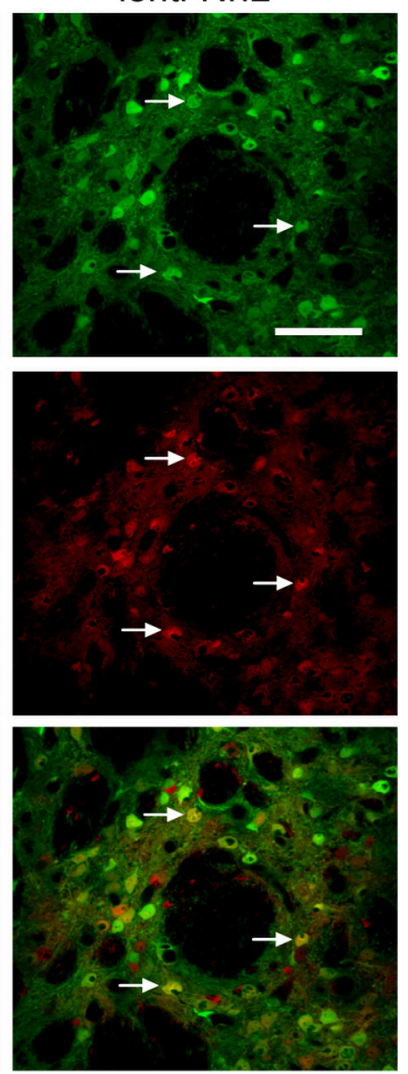

Figure 7. Lentivirus-mediated Nrf2 overexpression in neurons increases EAAT3 expression and GSH levels. WT mice received an injection of lenti-Nrf2 in the right striatum and lenti-LacZ (control) in the left striatum. Lenti-GFP was coinjected on each side to detect infected neurons, and brains were evaluated 1 month later. $A$, Lenti-Nrf2 increases Nrf2 and EAAT3 mRNA levels, $n=4$. ${ }^{*} p<$ 0.05 versus lenti-LacZ. B, Lenti-Nrf2 increases EAAT3 expression (red) in infected neurons (green). C, Lenti-Nrf2 increases neuronal GSH content (C5 maleimide staining; red) in infected neurons. Arrows show locations of GFP-labeled neuronal perikarya in the sections injected with lenti-Nrf2. Scale bar, $40 \mu \mathrm{m} . \boldsymbol{D}$, EAAT3 and C5 maleimide staining intensity in GFP ${ }^{+}$(infected) neurons. $n=$ 4. ${ }^{*} p<0.05$.

Almeida et al., 2001) to evaluate the effects of Nrf2 activation selectively in neurons. Lenti-Nrf2 induced a threefold increase in Nrf2 mRNA relative to the controlateral hemisphere injected with a control lentivirus encoding $\beta$-galactosidase (lenti-LacZ) (Fig. 7A). The lentivirus-mediated Nrf2 overexpression also increased EAAT3 mRNA in the area of injection (Fig. 7A). The increase in EAAT3 expression was also detectable by immunostaining (Fig. $7 B$ ) and colocalized with an increase in C5maleimide labeling (Fig. 7C). Infected neurons, detected by their expression of GFP, displayed a 50\% increase in EAAT3 staining and an 80\% increase in C5-maleimide staining relative to infected neurons in the contralateral striatum injected with lenti-LacZ (Fig. 7D).

\section{Discussion}

Neuronal GSH synthesis requires astrocyte release of GSH, extracellular cleavage of GSH to cysteine, and neuronal uptake of cysteine through EAAT3 (Dringen and Hirrlinger, 2003; Aoyama et al., 2008b). Nrf2 activation has been shown to increase astrocyte production and extracellular release of GSH by increasing the expression of enzymes and transporters involved in GSH metabolism (Shih et al., 2003; Kraft et al., 2004) (Fig. 8). The present findings show that activation of the Nrf2-ARE pathway in neurons produces a parallel upregulation of EAAT3 expression. Enhanced EAAT3 expression increases neuronal capacity to take up cysteine, the rate-limiting component in neuronal GSH synthesis. Neurons exposed to either the Nrf2-activating agent t-BHQ 


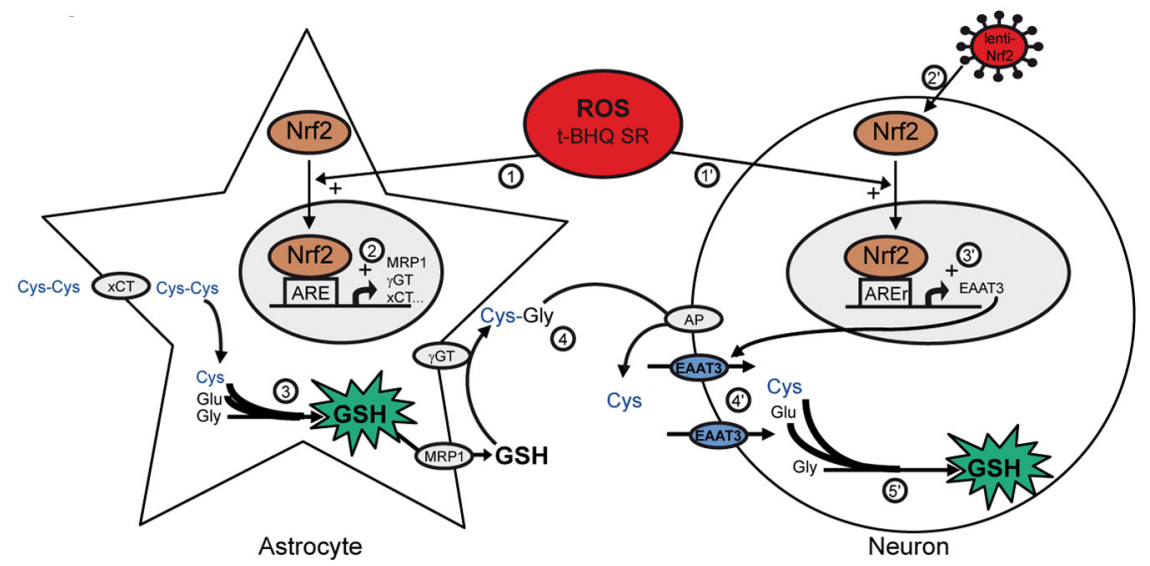

Figure 8. Nrf2 coordinates a multicellular response to oxidative stress in the brain. Nrf2 effects on astrocytes are well described (Shih et al., 2003; Vargas and Johnson, 2009): upon stimulation by reactive oxygen species (ROS) or by Nrf2 activators such as t-BHQ and SR, Nrf2 translocates to the astrocyte nucleus (1), binds to ARE sequences, and activates the transcription of multiple genes involved in GSH metabolism. These include the cystine (Cys-Cys) transporter xCT, the GSH extruder MRP1, and the GSH degrading ecto-enzyme $\gamma$-GT (2). The net effect is increased synthesis and release of GSH by astrocytes (3). GSH is cleaved by $\gamma$-GT and aminopeptidase (AP) to generate free cysteine (Cys), the rate-limiting precursor for GSH synthesis (4). Taking advantage of a lentiviral vector that targets neurons (lenti-Nrf2, 2'), we show that Nrf2 binds to an ARE-related sequence (AREr) in the EAAT3 promoter in neurons. Activation of neuronal Nrf2 by ROS, nucleophiles $\left(1^{\prime}\right)$, or Nrf2 overexpression ( $\left.2^{\prime}\right)$ activates EAAT3 transcription ( $\left.3^{\prime}\right)$. Increased EAAT3 levels facilitate neuronal uptake of cysteine $\left(4^{\prime}\right)$, thereby facilitating GSH production in neurons $\left(5^{\prime}\right)$.

or to lentivirus-mediated Nrf2 overexpression increased both EAAT3 expression and GSH content. The neuronal GSH increase following t-BHQ treatment was not observed in $E A A T 3^{-1-}$ mice, indicating that increased EAAT3 expression is required for the effect of Nrf2 on neuronal GSH content in brain.

The consensus ARE sequence was initially identified as $5^{\prime}$ rgTGACnnnGC-3' (Wang et al., 2007). Alternative, extended, and more versatile sequences also promote Nrf2-dependent activation of transcription (Erickson et al., 2002; Sasaki et al., 2002; Nioi et al., 2003; Wang et al., 2007). Here we identified a conserved ARE-related sequence in the EAAT3 promoter of several mammalian species. Using lentiviral gene transfer to induce neuronrestricted expression of HA-tagged Nrf2, we found by ChIP analysis that the ARE-related sequence in the EAAT3 promoter was bound by HA-tagged Nrf2 expressed selectively in brain neurons. An effect of Nrf2 on neuronal EAAT3 gene transcription was further supported by the finding that lentiviral Nrf2 gene transfer was sufficient to increase EAAT3 mRNA levels.

ARE-mediated gene transcription has been reported to be more robust in astrocytes than in neurons (Shih et al., 2003; Kraft et al., 2004; Vargas and Johnson, 2009), but several reports document a functional Nrf2 pathway in neurons of the brain and spinal cord (Johnson et al., 2002; Satoh et al., 2006; Kraft et al., 2007; Ramsey et al., 2007; Kanninen et al., 2009). Similarly, a gene expression study of neurons found EAAT3 (Slc1a1) mRNA levels to be lower in $N r f 2^{-1-}$ than in wild-type neuron cultures (Lee et al., 2003), which exhibit chronic oxidative stress (Johnson et al., 2002). Results of the present studies indicate that Nrf2 is required for upregulation of EAAT3, but not for basal expression of EAAT3, in both the in vitro and in vivo experimental models used. This pattern is consistent with that previously identified for multiple other genes involved in antioxidant defense (Malhotra et al., 2010).

Factors other than transcriptional regulation of EAAT3 may also impact Nrf2 effects on neuronal GSH synthesis. Prior reports have established EAAT3 surface translocation as an important regulator of EAAT3 transport activity (Robinson, 2006). EAAT3 surface expression can change substantially within minutes, and is regulated by protein kinase C and other factors (Fournier et al., 2004). Uptake of glutamate by EAAT3 may also contribute to GSH synthesis, although this amino acid is usually present in excess. Nrf2 may also upregulate expression of enzymes involved in GSH synthesis in neurons, as it does in other cell types (Lee et al., 2003). Nevertheless, the absence of an Nrf2-mediated increase in GSH in neurons of EAAT3 ${ }^{-/-}$mice establishes the importance of this transporter in the neuronal response to Nrf2 activation. Similarly, the absence of oxidant-induced changes in neuronal GSH content or EAAT3 expression in $\mathrm{Nrf2} 2^{-1-}$ mice indicates a central role for $\mathrm{Nrf} 2$ in mediating these responses to oxidative stress.

GSH histochemical staining and immunostaining showed highest GSH content in neuronal cell bodies, consistent with most prior studies of GSH distribution in brain (Ong et al., 2000). The specificity of the GSH signal observed here was confirmed in two independent imaging methods and by negative controls produced by inhibiting GSH synthesis. Both imaging methods showed a t-BHQ increased neuronal GSH content in wild-type but not $N r f 2^{-1-}$ neuronal perikarya, confirming action through the Nrf2-ARE pathway. These studies do not, however, establish whether t-BHQ also increased GSH content in the astrocyte compartment. While an increase in astrocytes would be expected, export of GSH from astrocytes may limit their GSH accumulation. Most importantly, failure of t-BHQ to increase GSH content in EAAT3 ${ }^{-/-}$mice despite activation of $\mathrm{Nrf} 2$ in both astrocytes and neurons establishes neuronal EAAT3 expression as an essential component of the Nrf2-ARE response in brain.

The control of brain extracellular cysteine concentration is surprisingly complex, involving GSH as an extracellular cysteine precursor and its cleavage by extracellular peptidases (Dringen and Hirrlinger, 2003) (Fig. 8). Consequently, GSH release by astrocytes must be coupled to an increase in neuronal cysteine uptake to fuel neuronal GSH synthesis. The reason for this complexity has not been established but may stem from the fact that free cysteine is a potent excitotoxin (Janáky et al., 2000). Immature neurons, like most other cell types, are able to take up cystine through system $\mathrm{X}_{\mathrm{c}}{ }^{-}$for GSH synthesis (Murphy et al., 1990), but mature neurons do not express $\mathrm{X}_{\mathrm{c}}{ }^{-}$ (Sato et al., 2002) and instead use EAAT3 as the major route for cysteine uptake (Aoyama et al., 2008b). Indeed, defects in EAAT3 function can trigger oxidative stress and neurodegeneration (Aoyama et al., 2006, 2008a; Nafia et al., 2008; Li et al., 2010). The present results suggest that Nrf2-induced EAAT3 expression in neurons parallels Nrf2-induced GSH release by astrocytes to facilitate neuronal cysteine and glutamate uptake and subsequent GSH synthesis (Fig. 8). The Nrf2-ARE pathway can thereby coordinate astrocyte and neuronal responses to oxidative stress. 


\section{References}

Alam J, Stewart D, Touchard C, Boinapally S, Choi AM, Cook JL (1999) Nrf2, a Cap 'n'Collar transcription factor, regulates induction of the heme oxygenase-1 gene. J Biol Chem 274:26071-26078.

Aoyama K, Suh SW, Hamby AM, Liu J, Chan WY, Chen Y, Swanson RA (2006) Neuronal glutathione deficiency and age-dependent neurodegeneration in the EAAC1 deficient mouse. Nat Neurosci 9:119-126.

Aoyama K, Matsumura N, Watabe M, Nakaki T (2008a) Oxidative stress on EAAC1 is involved in MPTP-induced glutathione depletion and motor dysfunction. Eur J Neurosci 27:20-30.

Aoyama K, Watabe M, Nakaki T (2008b) Regulation of neuronal glutathione synthesis. J Pharmacol Sci 108:227-238.

Bianchi MG, Gazzola GC, Cagnin S, Kagechika H, Bussolati O (2009) The ATRA-dependent overexpression of the glutamate transporter EAAC1 requires RARbeta induction. Biochim Biophys Acta 1788:1861-1868.

Chen Y, Swanson RA (2003) The glutamate transporters EAAT2 and EAAT3 mediate cysteine uptake in cortical neuron cultures. J Neurochem 84:1332-1339.

Comporti M (1989) Three models of free radical-induced cell injury. Chem Biol Interact 72:1-56.

Danbolt NC (2001) Glutamate uptake. Prog Neurobiol 65:1-105.

Davis KE, Straff DJ, Weinstein EA, Bannerman PG, Correale DM, Rothstein JD, Robinson MB (1998) Multiple signaling pathways regulate cell surface expression and activity of the excitatory amino acid carrier 1 subtype of Glu transporter in C6 glioma. J Neurosci 18:2475-2485.

de Almeida LP, Zala D, Aebischer P, Déglon N (2001) Neuroprotective effect of a CNTF-expressing lentiviral vector in the quinolinic acid rat model of Huntington's disease. Neurobiol Dis 8:433-446.

Déglon N, Tseng JL, Bensadoun JC, Zurn AD, Arsenijevic Y, Pereira de Almeida L, Zufferey R, Trono D, Aebischer P (2000) Self-inactivating lentiviral vectors with enhanced transgene expression as potential gene transfer system in Parkinson's disease. Hum Gene Ther 11:179-190.

Dringen R, Hirrlinger J (2003) Glutathione pathways in the brain. Biol Chem 384:505-516.

Dringen R, Gutterer JM, Gros C, Hirrlinger J (2001) Aminopeptidase N mediates the utilization of the GSH precursor CysGly by cultured neurons. J Neurosci Res 66:1003-1008.

Erecińska M, Wantorsky D, Wilson DF (1983) Aspartate transport in synaptosomes from rat brain. J Biol Chem 258:9069-9077.

Erickson AM, Nevarea Z, Gipp JJ, Mulcahy RT (2002) Identification of a variant antioxidant response element in the promoter of the human glutamate-cysteine ligase modifier subunit gene. Revision of the ARE consensus sequence. J Biol Chem 277:30730-30737.

Fournier KM, González MI, Robinson MB (2004) Rapid trafficking of the neuronal glutamate transporter, EAAC1: evidence for distinct trafficking pathways differentially regulated by protein kinase $\mathrm{C}$ and platelet-derived growth factor. J Biol Chem 279:34505-34513.

Himi T, Ikeda M, Yasuhara T, Nishida M, Morita I (2003) Role of neuronal glutamate transporter in the cysteine uptake and intracellular glutathione levels in cultured cortical neurons. J Neural Transm 110:1337-1348.

Hsu L, Rockenstein E, Mallory M, Hashimoto M, Masliah E (2001) Altered expression of glutamate transporters under hypoxic conditions in vitro. J Neurosci Res 64:193-202.

Huang Y, Zuo Z (2003) Isoflurane enhances the expression and activity of glutamate transporter type 3 in C6 glioma cells. Anesthesiology 99:1346-1353.

Itoh K, Chiba T, Takahashi S, Ishii T, Igarashi K, Katoh Y, Oyake T, Hayashi N, Satoh K, Hatayama I, Yamamoto M, Nabeshima Y (1997) An Nrf2/ small Maf heterodimer mediates the induction of phase II detoxifying enzyme genes through antioxidant response elements. Biochem Biophys Res Commun 236:313-322.

Janáky R, Varga V, Hermann A, Saransaari P, Oja SS (2000) Mechanisms of L-cysteine neurotoxicity. Neurochem Res 25:1397-1405.

Johnson DA, Andrews GK, Xu W, Johnson JA (2002) Activation of the antioxidant response element in primary cortical neuronal cultures derived from transgenic reporter mice. J Neurochem 81:1233-1241.

Kanai Y, Hediger MA (1992) Primary structure and functional characterization of a high-affinity glutamate transporter. Nature 360:467-471.

Kanninen K, Heikkinen R, Malm T, Rolova T, Kuhmonen S, Leinonen H, Ylä-Herttuala S, Tanila H, Levonen AL, Koistinaho M, Koistinaho J (2009) Intrahippocampal injection of a lentiviral vector expressing Nrf2 improves spatial learning in a mouse model of Alzheimer's disease. Proc Natl Acad Sci U S A 106:16505-16510.

Kraft AD, Johnson DA, Johnson JA (2004) Nuclear factor E2-related factor 2-dependent antioxidant response element activation by tertbutylhydroquinone and sulforaphane occurring preferentially in astrocytes conditions neurons against oxidative insult. J Neurosci 24:1101-1112.

Kraft AD, Resch JM, Johnson DA, Johnson JA (2007) Activation of the Nrf2-ARE pathway in muscle and spinal cord during ALS-like pathology in mice expressing mutant SOD1. Exp Neurol 207:107-117.

Lee JM, Shih AY, Murphy TH, Johnson JA (2003) NF-E2-related factor-2 mediates neuroprotection against mitochondrial complex I inhibitors and increased concentrations of intracellular calcium in primary cortical neurons. J Biol Chem 278:37948-37956.

Li X, Valencia A, Sapp E, Masso N, Alexander J, Reeves P, Kegel KB, Aronin N, Difiglia M (2010) Aberrant Rab11-dependent trafficking of the neuronal glutamate transporter EAAC1 causes oxidative stress and cell death in Huntington's disease. J Neurosci 30:4552-4561.

Livak KJ, Schmittgen TD (2001) Analysis of relative gene expression data using real-time quantitative PCR and the 2(-Delta Delta C(T)) method. Methods 25:402-408.

Ma K, Zheng S, Zuo Z (2006) The transcription factor regulatory factor X1 increases the expression of neuronal glutamate transporter type 3. J Biol Chem 281:21250-21255.

Malhotra D, Portales-Casamar E, Singh A, Srivastava S, Arenillas D, Happel C, Shyr C, Wakabayashi N, Kensler TW, Wasserman WW, Biswal S (2010) Global mapping of binding sites for Nrf2 identifies novel targets in cell survival response through ChIP-Seq profiling and network analysis. Nucleic Acids Res 38:5718 -5734.

Miller VM, Lawrence DA, Mondal TK, Seegal RF (2009) Reduced glutathione is highly expressed in white matter and neurons in the unperturbed mouse brain-implications for oxidative stress associated with neurodegeneration. Brain Res 1276:22-30.

Morgenstern B, Frech K, Dress A, Werner T (1998) DIALIGN: finding local similarities by multiple sequence alignment. Bioinformatics 14:290-294.

Murphy TH, Schnaar RL, Coyle JT (1990) Immature cortical neurons are uniquely sensitive to glutamate toxicity by inhibition of cystine uptake. FASEB J 4:1624-1633.

Nafia I, Re DB, Masmejean F, Melon C, Kachidian P, Kerkerian-Le Goff L, Nieoullon A, Had-Aissouni L (2008) Preferential vulnerability of mesencephalic dopamine neurons to glutamate transporter dysfunction. J Neurochem 105:484-496.

Nioi P, McMahon M, Itoh K, Yamamoto M, Hayes JD (2003) Identification of a novel Nrf2-regulated antioxidant response element (ARE) in the mouse $\mathrm{NAD}(\mathrm{P}) \mathrm{H}$ :quinone oxidoreductase 1 gene: reassessment of the ARE consensus sequence. Biochem J 374:337-348.

O'Geen H, Frietze S, Farnham PJ (2010) Using ChIP-seq technology to identify targets of zinc finger transcription factors. Methods Mol Biol 649:437-455.

Ong WY, Hu CY, Hjelle OP, Ottersen OP, Halliwell B (2000) Changes in glutathione in the hippocampus of rats injected with kainate: depletion in neurons and upregulation in glia. Exp Brain Res 132:510-516.

Pugazhenthi S, Akhov L, Selvaraj G, Wang M, Alam J (2007) Regulation of heme oxygenase- 1 expression by demethoxy curcuminoids through Nrf2 by a PI3-kinase/Akt-mediated pathway in mouse beta-cells. Am J Physiol Endocrinol Metab 293:E645-655.

Ramsey CP, Glass CA, Montgomery MB, Lindl KA, Ritson GP, Chia LA, Hamilton RL, Chu CT, Jordan-Sciutto KL (2007) Expression of Nrf2 in neurodegenerative diseases. J Neuropathol Exp Neurol 66:75-85.

Rhinn H, Marchand-Leroux C, Croci N, Plotkine M, Scherman D, Escriou V (2008) Housekeeping while brain's storming Validation of normalizing factors for gene expression studies in a murine model of traumatic brain injury. BMC Mol Biol 9:62.

Robinson MB (2006) Acute regulation of sodium-dependent glutamate transporters: a focus on constitutive and regulated trafficking. Handb Exp Pharmacol 251-275.

Sasaki H, Sato H, Kuriyama-Matsumura K, Sato K, Maebara K, Wang H, Tamba M, Itoh K, Yamamoto M, Bannai S (2002) Electrophile response element-mediated induction of the cystine/glutamate exchange transporter gene expression. J Biol Chem 277:44765-44771. 
Sato H, Tamba M, Okuno S, Sato K, Keino-Masu K, Masu M, Bannai S (2002) Distribution of cystine/glutamate exchange transporter, system $\mathrm{x}(\mathrm{c})-$, in the mouse brain. J Neurosci 22:8028-8033.

Satoh T, Okamoto SI, Cui J, Watanabe Y, Furuta K, Suzuki M, Tohyama K, Lipton SA (2006) Activation of the Keap1/Nrf2 pathway for neuroprotection by electrophilic phase II inducers. Proc Natl Acad Sci U S A 103:768-773.

Shih AY, Johnson DA, Wong G, Kraft AD, Jiang L, Erb H, Johnson JA, Murphy TH (2003) Coordinate regulation of glutathione biosynthesis and release by Nrf2-expressing glia potently protects neurons from oxidative stress. J Neurosci 23:3394-3406.

Smith PK, Krohn RI, Hermanson GT, Mallia AK, Gartner FH, Provenzano MD, Fujimoto EK, Goeke NM, Olson BJ, Klenk DC (1985) Measurement of protein using bicinchoninic acid. Anal Biochem 150:76-85.

Vargas MR, Johnson JA (2009) The Nrf2-ARE cytoprotective pathway in astrocytes. Expert Rev Mol Med 11:e17.
Vargas MR, Pehar M, Cassina P, Martínez-Palma L, Thompson JA, Beckman JS, Barbeito L (2005) Fibroblast growth factor-1 induces heme oxygenase-1 via nuclear factor erythroid 2-related factor 2 (Nrf2) in spinal cord astrocytes: consequences for motor neuron survival. J Biol Chem 280:25571-25579.

Wang X, Tomso DJ, Chorley BN, Cho HY, Cheung VG, Kleeberger SR, Bell DA (2007) Identification of polymorphic antioxidant response elements in the human genome. Hum Mol Genet 16:1188-1200.

Watabe M, Aoyama K, Nakaki T (2008) A dominant role of GTRAP3-18 in neuronal glutathione synthesis. J Neurosci 28:9404-9413.

Won SJ, Yoo BH, Brennan AM, Shin BS, Kauppinen TM, Berman AE, Swanson RA, Suh SW (2010) EAAC1 gene deletion alters zinc homeostasis and exacerbates neuronal injury after transient cerebral ischemia. J Neurosci 30:15409-15418.

Zerangue N, Kavanaugh MP (1996) Interaction of L-cysteine with a human excitatory amino acid transporter. J Physiol 493:419-423. 